\title{
COVID-19 after hematopoietic stem cell transplantation: report of two children
}

\author{
Gabriele Zamperlini-Netto $\mathbb{1}^{1}$ • Juliana Folloni Fernandes ${ }^{1}$ - Julia Lopes Garcia ${ }^{1}$ Andreza Alice Feitoza Ribeiro ${ }^{1}$.

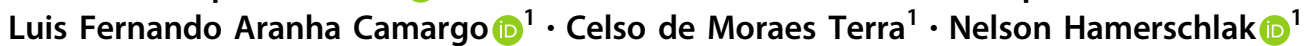

Received: 27 May 2020 / Revised: 4 August 2020 / Accepted: 18 August 2020 / Published online: 16 September 2020

C Springer Nature Limited 2020

\section{To the Editor:}

The COVID-19 pandemic caused by SARS-CoV-2 has been responsible for more than 646 thousand deaths, among over 16 million cases across the globe as of July 27, 2020 [1]. Since its first report in December of 2019 [2], knowledge about the epidemiology and pathophysiology of the disease has been increasing. Although elderly and people with comorbidities are the most affected by the severe manifestations of the disease [3], new clinical presentations and management challenges continue to evolve on an almost daily basis. The pediatric population seems to present with less severe clinical behavior compared to the adult population [4]. However, little is known about children and adolescents with underlying conditions [5]. We report here the cases of two pediatric patients diagnosed with COVID-19 following hematopoietic stem cell transplantation, therefore under immunosuppression when infected with the virus.

\section{Case 1}

A 2-year-old boy with acute myeloid leukemia (AML) with central nervous system involvement in first complete remission was submitted to an allogeneic bone marrow transplant in September 2019 from a matched unrelated donor. The boy weighed $13 \mathrm{~kg}$. The myeloablative conditioning regimen contained busulfan (cumulative area under the curve, AUC: $85 \mathrm{mg} \times \mathrm{h} / \mathrm{L})$, fludarabine $\left(150 \mathrm{mg} / \mathrm{m}^{2}\right)$, thiotepa $(5 \mathrm{mg} / \mathrm{Kg})$ and rabbit anti-thymocyte globulin $(7.5 \mathrm{mg} / \mathrm{Kg})$. Standard cyclosporine $(3 \mathrm{mg} / \mathrm{kg}$ aiming a

Nelson Hamerschlak

hamer@einstein.br

1 Hospital Israelita Albert Einstein, Avenida Albert Einstein, 627, Morumbi, São Paulo, SP CEP: 05652-900, Brazil trough level around $200 \mathrm{ng} / \mathrm{ml})$ and methotrexate $\left(10 \mathrm{mg} / \mathrm{m}^{2}\right.$ on Days 1, 3, and 6) were the graft-versus-host-disease (GVHD) prophylaxis. On Day 40, the patient developed grade-3 acute GVHD involving the skin, gastrointestinal (GI), and liver, which was refractory to methylprednisolone ( $2 \mathrm{mg} / \mathrm{Kg}$ ). Therefore ruxolitinib ( $2.5 \mathrm{mg}$ orally, twice a day) was started on day 48. Because of persistent gastrointestinal and liver GVHD, extracorporeal photopheresis biweekly was started on Day 68, with gradual improvement, achieving remission of the skin, gastrointestinal tract, and liver GVHD by day 100 (after 9 sessions).

The boy subsequently started with increasing respiratory distress (wheezing, cough, and hypoxemia). Radiological findings consistent with bronchiolitis obliterans syndrome were seen on day 110. There were no signs of infection, radiological or otherwise, and unfortunately, spirometry could not be performed due to his young age, neither biopsy. High dose methylprednisolone $(10 \mathrm{mg} / \mathrm{Kg}$ per day, for 3 days every 4 weeks) associated with prednisolone $(1 \mathrm{mg} / \mathrm{Kg} /$ day $)$ was given in the interim, azithromycin $(10 \mathrm{mg} / \mathrm{Kg} /$ day $)$ and inhaled fluticasone $(250 \mathrm{mcg}$ twice a day) were started while on cyclosporine and ruxolitinib (maintaining the same dosage).

On day 180, he was admitted to the intensive care unit (ICU) due to worsening of his respiratory status after a rhinovirus infection and was placed on high flow nasal cannulae. On March 31st (Day 204) his mother started with a fever and sore throat. For personal and familiar reasons, the mother had been isolated with the child since hospital admission, before the onset of the COVID-19 outbreak in Brazil. Both the child and his mother were diagnosed with COVID-19 infection by RT-PCR exam (real-time polymerase chain reaction, analyzed through Applied Biosystems equipment in the hospital) with the sample collected through a nasopharyngeal swab. Given the concern regarding the poor lung condition, hydroxychloroquine $(6.5 \mathrm{mg} / \mathrm{Kg}$ orally, twice a day) was started. His clinical course, different from his mother's, was completely asymptomatic for COVID-19, 
and hydroxychloroquine was interrupted 7 days after it was started. He stayed under immunosuppression. He was not receiving intravenous immunoglobulin replacement and the immune recovery 15 days before COVID-19 diagnosis

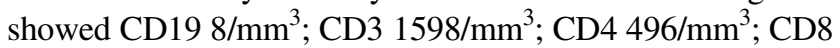
$1067 / \mathrm{mm}^{3}$; and natural killer, $\mathrm{NK} 48 / \mathrm{mm}^{3}$.

Chest computed tomography was not performed due to general anesthetic (GA) requirement and occupational/ environmental exposure concerns. The weekly nasopharyngeal RT-PCR was still positive five weeks after COVID19 was first detected and serology performed weekly, revealed immunoglobulin $\mathrm{M}$ (IgM) positivity with negative immunoglobulin $\mathrm{G}$ ( $\mathrm{IgG}$ ) only after 4 weeks. The patient remained in the hospital for the management of the conditions he had before COVID-19 (bronchiolitis obliterans syndrome and oxygen dependence).

\section{Case 2}

A 17-month-old girl, weighing $6.2 \mathrm{~kg}$, was diagnosed with a JAK3-deficient severe combined immunodeficiency after recurrent pneumonia episodes she had since she was 4 months of age and disseminated BCGosis (Calmette-Guerin bacillus infection) at 7 months. In October 2019 (at 11 months of age) she was referred for an allogeneic stem cell transplantation from a matched unrelated donor. After a reduced toxicity conditioning regimen with fludarabine $\left(180 \mathrm{mg} / \mathrm{m}^{2}\right)$, busulfan (AUC: $85 \mathrm{mg} \mathrm{x} \mathrm{h/L)} \mathrm{and} \mathrm{rabbit} \mathrm{anti-thymocyte} \mathrm{globulin} \mathrm{(7.5}$ $\mathrm{mg} / \mathrm{kg}$ ); cyclosporin ( $3 \mathrm{mg} / \mathrm{kg}$ aiming for a trough level around $200 \mathrm{ng} / \mathrm{ml}$ ) and mycophenolate mofetil (MMF, $15 \mathrm{mg} / \mathrm{Kg}$ every $8 \mathrm{~h}$ ) were used for GVHD prophylaxis. The course of her transplant was characterized by disseminated BCGosis just after engraftment, and that was likely related to the immune reconstitution. The treatment included the three classical drugs rifampicin $(15 \mathrm{mg} / \mathrm{Kg}$ once daily), isoniazid $(10 \mathrm{mg} / \mathrm{Kg}$ once daily) and ethambutol (20 mg/Kg once daily), with levofloxacin $(15 \mathrm{mg} / \mathrm{Kg}$ daily), amikacin $(15 \mathrm{mg} / \mathrm{Kg}$ daily) and, because of significant inflammatory symptoms related to multiple subcutaneous BCG nodules, she also received intermittent and short courses of prednisolone ( $1 \mathrm{mg} / \mathrm{Kg} /$ day $)$.

Since day 67, an acute Epstein Barr infection was successfully treated with four weekly doses of rituximab (375 $\mathrm{mg} / \mathrm{m}^{2}$ ). The infection was characterized by persistent fever, significant splenomegaly, and quantitative PCR for EBV in plasma higher than 230,000 copies/ml. a PET-CT revealed splenic and mediastinal lymph nodes uptake. Potentially it could represent a post-transplant lymphoproliferative disorder, but a biopsy was not performed due to surgical risks at that time. There was no evidence for GVHD or other transplant-related complications. MMF was discontinued on day 60 and cyclosporin was the immunosuppression used along the first 180 days post transplant.
On March 30 she was admitted to the bone marrow transplant ward with fever. At the time of her admission, with her mother, there were suspicions of SARS-CoV-2 infection in her family. Her nasopharyngeal COVID-19 RT-PCR resulted positive on Day 167 (March 31), and she was started on hydroxychloroquine $(6.5 \mathrm{mg} / \mathrm{Kg}$ orally, twice a day) and azithromycin $(10 \mathrm{mg} / \mathrm{Kg} / \mathrm{day})$. The chest $\mathrm{CT}$ was postponed because of the same reasons pointed in case 1 (the need for general anesthetic and concerns about exposure).

She remained febrile for 10 days, without any respiratory or systemic symptoms throughout the hospital admission, not requiring intensive care. Treatment was interrupted after 7 days, and the patient was discharged home after 15 days with no complications. The patient was receiving intravenous immunoglobulin every 4 weeks and the immune recovery status at the time she was diagnosed with COVID-

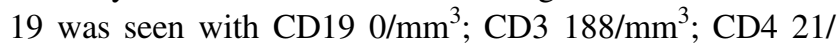
$\mathrm{mm}^{3}$; CD8 146/ $\mathrm{mm}^{3}$; NK $211 / \mathrm{mm}^{3}$. The nasopharyngeal RT-PCR was still positive five weeks after COVID-19 was first detected. Serology has never shown immune response throughout the clinical course, with serum $\operatorname{IgM}$ and $\operatorname{IgG}$ both negative for COVID-19 by week 5 .

\section{Discussion}

COVID-19 has a wide spectrum of clinical presentation and severity. The respiratory distress is the striking aspect responsible for elevated mortality, but there is increasing evidence that an inflammatory status with cytokine storm and hypercoagulability contribute to the pathophysiology of a systemic disease, rather than a pulmonary infection only $[6,7]$. Some new and worrisome complications such as stroke [8] and Kawasaki syndrome [9] corroborate to that hypothesis. Although children and adolescents seem to be spared of the more aggressive or severe form of the COVID-19, the natural history of the SARS-Cov-2 in pediatric patients with chronic conditions, especially those under cancer treatment and post transplant is largely unknown [10].

Respiratory viruses are historically a matter of concern for transplant and cancer centers given its association with significant morbidity and mortality [11]. The few publications so far showed a very low incidence of complications in immunosuppressed patients infected by SARS-Cov-2. Among 171 children diagnosed with SARS-CoV-2 from Wuhan, only 1 patient in chemotherapy treatment for acute lymphoblastic leukemia required intensive care support [4]. In a survey conducted in 32 centers treating pediatric patients with cancer or immunosuppressive agents, only 8 patients were tested positive for COVID-19 and none of these required intensive care [12]. The low rate of infection in pediatric patients with cancer could have several 
hypothetical explanations: first would be a bias in the collection of epidemiological data, or different surveillance strategies for patients with and without symptoms. It could also reflect more restrictive environmental approaches (isolation) in BMT units, adopted by our center according to recommendations from EBMT (European Society for Blood and Marrow Transplantation) for COVID-19: visiting restrictions (with no external visitors allowed in our transplant unit) and isolation of one parent together with the hospitalized children [13]. This could potentially have reduced the viral load (although not completely prevent infection). The recommended immunosuppressive prophylaxis might have had beneficial effects on inflammation too.

At the same time, the low incidence of complications might be a reflection of what is observed in the general population regarding age (elderly having more severe disease than young patients and children). However, it could also raise the question of an immune system not capable of triggering a major inflammatory response, although this cannot be stated given different experiences with patients after kidney transplants [14].

Treatments are also controversial for COVID-19, and new studies are continuously published [15]. As the first Brazilian COVID-19 case was diagnosed on February 26,2020 , very weak evidence was available yet when both of our patients were diagnosed regarding the proper management of the disease, especially those under chronic conditions in which individualized approach may be necessary.

Interestingly, both our patients remained with PCR positivity for SARS-CoV-2 after 5 weeks from diagnosis and did not develop IgG antibodies. This might be due to incomplete immunological reconstitution after transplant and to the fact that they are still on immunosuppressive therapy. Although we cannot measure the viral load and active virus replication, this situation has to be considered when planning isolation measures to prevent virus dissemination.

In conclusion, we report on the cases of two pediatric patients after hematopoietic stem cell transplant and heavily immunosuppressed who had a benign clinical course of COVID-19. It is reasonable to speculate about the degree of immunosuppression and the lack of immune response obviating the severe spectrum of the disease, although this conclusion cannot be definitive. The proper understanding of COVID-19 in patients under cancer treatment and immunosuppressive drugs depends on prospective and collaborative efforts.

\section{Compliance with ethical standards}

Conflict of interest The authors declare that they have no conflict of interest.
Publisher's note Springer Nature remains neutral with regard to jurisdictional claims in published maps and institutional affiliations.

\section{References}

1. WHO. Coronavirus disease. World Heal Organ. 2020;2019:2633. https://www.who.int/emergencies/diseases/novel-coronavirus2019.

2. Zhu N, Zhang D, Wang W, Li X, Yang B, Song J, et al. A novel coronavirus from patients with pneumonia in China, 2019. N. Engl J Med. 2020;382:727-33.

3. Chen N, Zhou M, Dong X, Qu J, Gong F, Han Y, et al. Epidemiological and clinical characteristics of 99 cases of 2019 novel coronavirus pneumonia in Wuhan, China: a descriptive study. Lancet. 2020;395:507-13. https://doi.org/10.1016/S0140-6736 (20)30211-7.

4. Lu X, Zhang L, Du H, Zhang J, Li YY, Qu J, et al. SARS-CoV-2 infection in children. N. Engl J Med. 2020;382:1663-5. https:// doi.org/10.1056/NEJMc2005073.

5. Kotecha RS. Challenges posed by COVID-19 to children with cancer. Lancet Oncol. 2020;21:e235. https://doi.org/10.1016/ S1470-2045(20)30205-9.

6. Liu J, Zheng X, Tong Q, Li W, Wang B, Sutter K, et al. Overlapping and discrete aspects of the pathology and pathogenesis of the emerging human pathogenic coronaviruses SARS-CoV, MERS-CoV, and 2019-nCoV. J Med Virol. 2020;92:491-4. https://doi.org/10.1002/jmv.25709.

7. Connors JM, Levy JH. COVID-19 and its implications for thrombosis and anticoagulation. Blood. 2020. https://doi.org/10. 1182/blood.2020006000.

8. Oxley TJ, Mocco J, Majidi S, Kellner CP, Shoirah H, Singh IP, et al. Large-vessel stroke as a presenting feature of Covid-19 in the young. N Engl J Med. 2020;382:e60. https://doi.org/10.1056/ NEJMc2009787.

9. Jones VG, Mills M, Suarez D, Hogan CA, Yeh D, Bradley Segal J, et al. COVID-19 and Kawasaki disease: novel virus and novel case. Hosp Pediatr. 2020;10:537-40.

10. Shekerdemian LS, Mahmood NR, Wolfe KK, Riggs BJ, Ross CE, McKiernan CA, et al. Characteristics and outcomes of children with Coronavirus Disease 2019 (COVID-19) Infection Admitted to US and Canadian Pediatric Intensive Care Units. JAMA Pediatr. 2020;174:868-73.

11. Fontana L, Strasfeld L. Respiratory virus infections of the stem cell transplant recipient and the hematologic malignancy patient. Infect Dis Clin North Am. 2019;33:523-44. http://www. sciencedirect.com/science/article/pii/S0891552019300078.

12. Hrusak O, Kalina T, Wolf J, Balduzzi A, Provenzi M, Rizzari C, et al. Flash survey on severe acute respiratory syndrome coronavirus-2 infections in paediatric patients on anticancer treatment. Eur J Cancer. 2020;132:11-6.

13. Ljungman $\mathrm{P}$, Mikulska $\mathrm{M}$, de la Camara R, Basak GW, Chabannon C, Corbacioglu S, et al. The challenge of COVID-19 and hematopoietic cell transplantation; EBMT recommendations for management of hematopoietic cell transplant recipients, their donors, and patients undergoing CAR T-cell therapy. Bone Marrow Transpl. 2020. https://doi.org/10.1038/s41409-020-0919-0.

14. Akalin E, Azzi Y, Bartash R, Seethamraju H, Parides M, Hemmige V, et al. Covid-19 and kidney transplantation. N Engl J Med. 2020. https://doi.org/10.1056/NEJMc2011117.

15. Geleris J, Sun Y, Platt J, Zucker J, Baldwin M, Hripcsak G, et al. Observational study of hydroxychloroquine in hospitalized patients with Covid-19. N Engl J Med. 2020;1-8. http://www. ncbi.nlm.nih.gov/pubmed/32379955. 